\title{
The Lipid Bilayer of Biological Vesicles: A Liquid-Crystalline Material as Nanovehicles of Information
}

\author{
Annette Alfsen ${ }^{*}$, Irène Tatischeff ${ }^{2}$ \\ ${ }^{1}$ CNRS Honorary Research Director, Paris, France \\ ${ }^{2}$ CNRS \& UPMC Honorary Research Director, Paris, France \\ Email: *annette.alfsen@orange.fr
}

Received 22 January 2014; revised 9 March 2014; accepted 26 March 2014

Copyright (C) 2014 by authors and Scientific Research Publishing Inc.

This work is licensed under the Creative Commons Attribution International License (CC BY). http://creativecommons.org/licenses/by/4.0/

\section{Open Access}

\begin{abstract}
The biological intracellular vesicles, formed from the cell membrane or from different cell organelles, play a main role in the intracellular transport, transfer and exchange of molecules and information. Extracellular vesicles are also detected in organisms belonging to any of the three main branches of evolution, Archaea, Bacteria and Eukarya. There is an increasing consensus that these vesicles are important mediators of intercellular communication. All the intracellular and extracellular vesicles present a characteristic lipid composition and organization that governs their formation, targeting and function. This paper gives an overview of the lipid chemical and physical structure, strongly related to their biological function. The properties and role of the different types of lipids from membranes and vesicles are described. Then, their physical structure is shown as self-associated in a bilayer and organized as a lyotropic liquid crystal. The present paper underlies the structural similarity between these biological vesicles and a new synthetic material, the "liquid crystalline fullerodendrimers" obtained from the biological model. It is composed of a basket of carbon associated with a liquid crystalline material and has been shown to exhibit highly efficient properties of information transfer. Our observation stresses the essential role of the liquid crystalline structure of lipids in their function as biological nanovehicles of information. The comparison with the synthetic material contributes to a better understanding of the role of lipids for cell communication in living organisms.
\end{abstract}

\section{Keywords}

Coated Vesicles; Extracellular Vesicles; Lipid Bilayer; Liquid Crystalline Material

\footnotetext{
*Corresponding author.
}

How to cite this paper: Alfsen, A. and Tatischeff, I. (2014) The Lipid Bilayer of Biological Vesicles: A Liquid-Crystalline Material as Nanovehicles of Information. Journal of Biomaterials and Nanobiotechnology, 5, 105-115. 


\section{Introduction}

Living matter components execute, in living creatures, a harmonious dance to a music, the rhythm of which governs each instant of cell life and whose harmony allows the life to exist in "the silence of the organs". From the organism to the organ, from the organ to its cells, from the cell to the organelles and down to each molecular component of the living matter, life is the result of concerted movements in both spatial and temporal dimensions.

Among the organelles that govern intercellular communication, the cell membrane, a structure of lipid molecules organized in an asymmetric bilayer in interaction with proteins and in contact with both the external surroundings and the internal aqueous solvent and solutes, is the master of this interplay. Cell membranes from unicellular or pluricellular organisms constantly form lipid vesicles, which either move internally from the cell membrane to sites within the cell and back, or which are externalized from the cell into the surrounding environment. All this vesicular traffic governs the transport of materials and the transfer of information.

\section{From the Unicellular Organisms to the Central Nervous System of Mammalians}

Cell membranes, as well as vesicle production, are suggested to be present at the origin of the Last Universal Cell Ancestor (LUCA), a putative cell type about 3.6 billion years old [1]. From the prokaryotic unicellular organisms to primitive eukaryotes at the border between the vegetal and animal kingdoms, like the amoebae Dictyostelium discoideum [2] and the algae [3], up to mammalian cells [4], the formation of intracellular and extracellular membrane vesicles of different sizes, origin and functions (Figure 1) has been shown to be a property of almost all cell types. In all cases, whether intra- or intercellularly, the vesicles function as nanovehicles for transport and transfer of material and information.
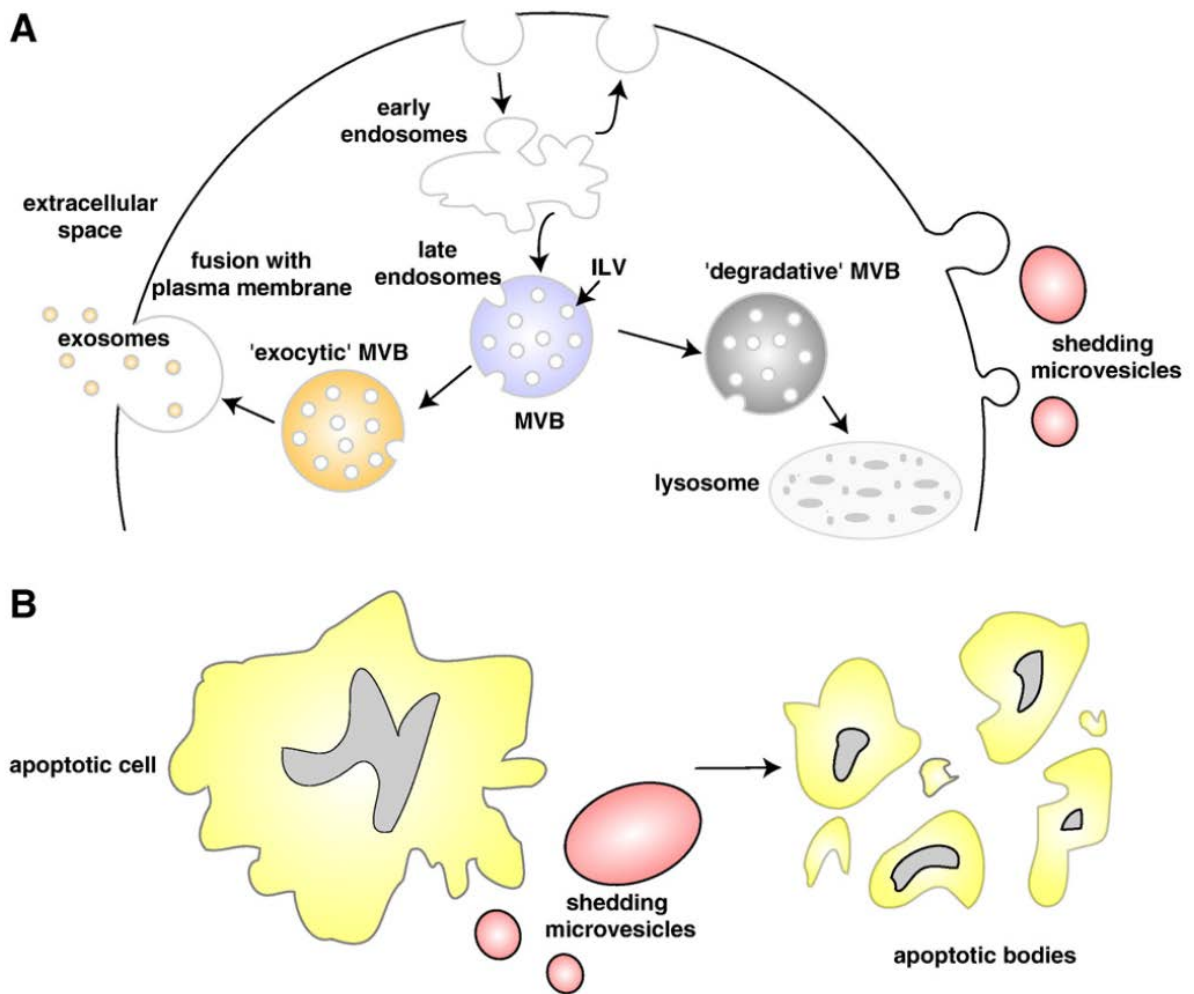

Figure 1. Schematic representation of the release of extracellular membranous microvesicles into the extracellular space. A: Release of exosomes, following intracellular endocytic traffic, and shedding of microvesicles from the plasma membrane. B: Shedding of microvesicles from the plasma membrane and generation of apoptotic bodies from apoptotic dying cells. Figure reproduced with permission from [24]—-see for details. 


\subsection{Intracellular Vesicles and Molecular Traffic}

The essential role of intracellular vesicles formed from the cell membrane or from different cell organelles in the intracellular traffic has very recently been emphasized by the attribution of the 2013 Nobel price to Rothman, Südhof and Schekman. Indeed, many intracellular vesicles, such as clathrin-coated vesicles (Figure 2) [5] [6], vesicles from Golgi [7] [8] and synaptic vesicles [9] [10] have been thoroughly studied.

All these vesicles play a main role in the transport, transfer and exchange of molecules and information throughout the different cell organelles. They present a characteristic lipid composition and organization that govern their formation, targeting and function. It is worth noting that the lipid composition of the vesicles is often different from that of the cell membranes from which they derive [11] [12], with specific lipid recruitment and/or exclusion.

\subsection{Extracellular Vesicles as Mediators of Cell Communication}

Extracellular vesicles are detected in organisms belonging to any of the three main branches of evolution: Archaea, Bacteria and Eukarya.

\subsubsection{Archaea}

In the Archaea of the order Thermococcales, "virus-like" vesicles were recently described [13], with unique similar morphologies as those observed in enrichment cultures of anaerobic hyperthermophilic Archaea from deep-sea vents. Whereas these particles appeared associated with cellular DNA, highly resistant to DNAse treatment and heat denaturation, the authors were unable to isolate viruses from these strains of Archaea, but they observed that most of the tested strains produce "virus-like vesicles" of different structures. As some of these vesicles were very similar to membranes vesicles produced by bacterial species, they suggested that production of membrane vesicles might be a widespread feature of the microbial word.

\subsubsection{Bacteria}

Many gram-negative bacteria use extracellular signals to communicate and coordinate social activities. It has been described that the cell walls of gram-negative bacteria possess a dynamic feature that is not seen in their gram-positive counterparts [14]: outer membrane vesicles are constantly being discharged from the surface of the cell during bacterial growth. Such a phenomenon has to be related to the structure of the gram-negative bacteria outer membrane (as well as the plasma membrane). Indeed, they possess a lipid-rich outer membrane and a thin peptidoglycan layer that separates the external environment from the periplasm. This outer membrane contains proteins, phospholipids, and lipopolysaccharides (LPS). The lipid bilayer constituents of these bacteria, are fluid and in continual rapid motion. At the nanoscale level, components such as LPS are constantly in motion. They move at high speeds laterally around the cell, and they are, at the same time, rotating on their long axes. Even the O-side chains are flexing back and forth and seem to be driven entirely by entropy. Environmental conditions (e.g., temperature) and molecular associations affect free motion.

Such characteristics allow the formation and release of vesicles. In these, the outer membrane of the bacterium is abruptly changed to the high-curvature form of the vesicle, but LPS and phospholipids are still integral

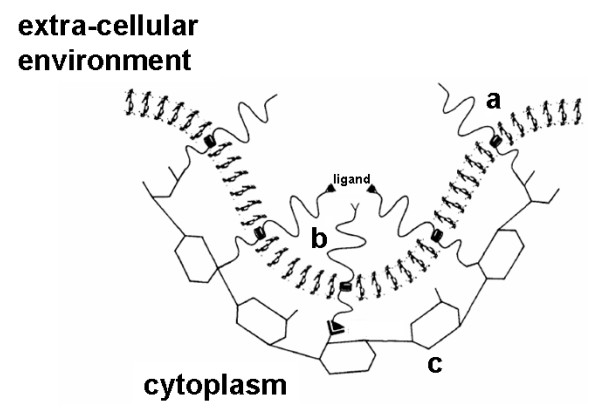

A

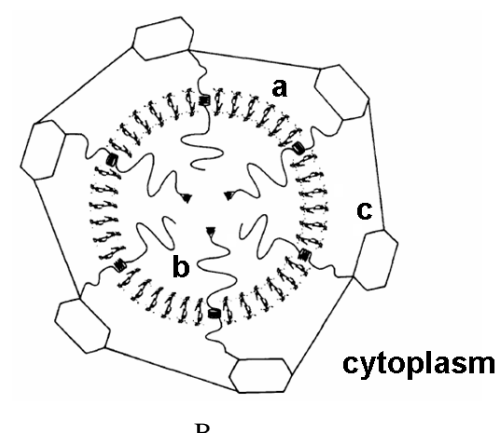

B

Figure 2. Schematic representation of clathrin coated vesicles [5]. A: membrane budding with the formation of the clathrin network; a) lipid bilayer b) inserted proteins c) clathrin network; B: coated vesicles with internalized material (a, b, c, as in A). 
constituents of the vesicle bilayer, with the phospholipid asymmetry retained. By electron microscopy, vesicles appear spherical with a bilayer membrane, electron-dense luminal content, and an average diameter of 50 - 250 $\mathrm{nm}$, depending on the bacterial strain. Extracellular secretion of products is the major mechanism by which gram-negative pathogens communicate with and intoxicate host cells, signaling molecules being packaged into membrane vesicles that serve to traffic those molecules within a bacterial population. Removal of these vesicles from the bacterial population halts cell-cell communication.

These findings illustrate a novel mechanism for delivery of a signal critical for coordinating group behavior in Pseudomonas aeruginosa, indicating that a prokaryote possesses a signal trafficking system with features common to those used by higher organisms [15]. By virtue of their characteristic lipid composition, leading to small size, adhesive properties, and ability to carry and deliver toxic components into host cells, outer membrane vesicles are likely to play a significant role in disseminating virulence factors for gram-negative pathogens [16].

\subsubsection{Eukarya}

\section{1) Dictyostelium discoideum}

In the Eukarya branch of the evolutionary tree, Dictyostelium discoideum, an ancestral non-pathogenic amoeba, placed at the border between the plant and animal kingdoms, is equipped with a lipid membrane that plays a critical role in many aspects of cell development. Extracellular vesicles, detected in the surrounding medium [2] [17] [18], have been shown to play the role of vehicles for intercellular communication. Lipid analysis of the bilayer surrounding the vesicles showed [2] beside the phospholipids and lipids common in the plasma membrane: PC, PI, PS and PE, sphingomyelin, PG and DPG, the presence of lyso bis-phosphatidic acid (LBPA), a lipid inducing membrane fusion [19] [20]. Such data emphasize the role of the nature of the lipids in the formation and function of the vesicles of the amoebae Dictyostelium.

All the other characteristics of $D$. discoideum extracellular vesicles and their use for drug delivery have already been described [17] [21] [22].

2) Mammalian cells

Membrane extracellular vesicles (see [23] [24]) (Figure 1) have been described as originating from almost all mammalian cell types: human blood cells (platelets [25], B lymphocytes [26], dendritic cells [27]-[29], but also from intestinal epithelial cells [30] or from different pathological cells [4].

They are MVB-derived exosomes [31]-[36] (Figure 1A), microvesicles originating from plasma membrane budding [37] (Figure 1A), or apoptotic bodies (Figure 1B).

\subsubsection{Virus}

Although not belonging to the above classes, but detected in the three branches of evolution, viruses are indeed also particles that may possess a lipid bilayer and an envelope [38]. They behave similarly to the membrane vesicles from bacteria by transferring their genetic material content.

The genetic material of viruses is either surrounded by a protein shell and/or by a bilayer of lipid originating from the host cell in which the virus replicated. Budding of these enveloped viruses occurs either from the plasma membrane or from intracellular compartments. As the lipid composition of the plasma membrane differs significantly from that of intracellular compartments, virus budding is probably dictated by the lipid composition of the membrane from which it buds [39]. Together with the lipid sorting occurring during the enveloped virus budding, it suggests that viral lipid composition plays an important role in enveloped virus function / pathogenicity [40]-[42].

\section{Properties and Role of Different Types of Lipids}

The lipids common to most of the cell membranes contribute by their different properties to the membrane functions.

\subsection{Phospholipids}

The phospholipids that comprise the major part of all lipids in the cell membranes [34] [42] [43] are characterized by the nature of their charged polar heads, the length of the hydrocarbon tails and the nature of the fatty acyl chains, whether saturated or polyunsaturated. The network of charged polar heads, positive, negative, or neutral, constitutes the barrier of electrical potential that interacts with the external and internal aqueous me- 


\section{A}

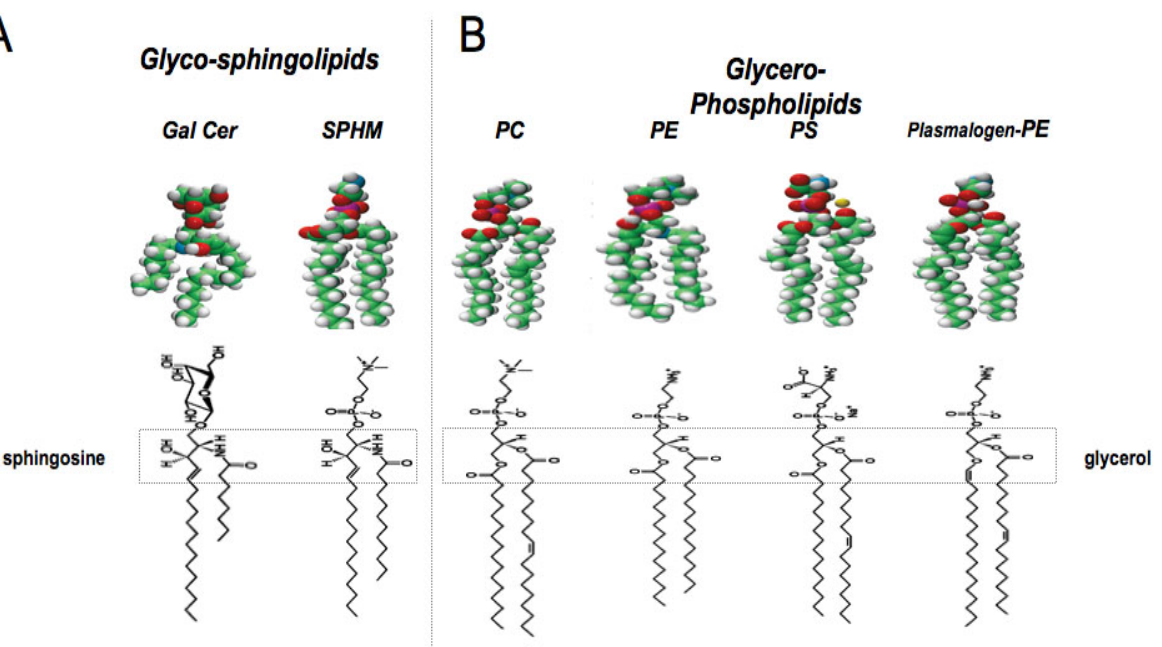

Figure 3. Molecular representation of the lipids. A: Glycosphingolipids: Gal Cer: galactosylceramide; SPHM: sphingomyelin B: Glycerophospholipids: PC: Phosphatidylcholine; PE: Phosphatidylethanolamine; PS: Phosphatidylserine; PL-PE: Plasmalogen-Phosphatidylethanolamine.

dium, i.e. ions and all solutes [44].

\subsection{Glycolipids-Sphingolipids}

It is currently accepted that cell signalization (intra- and intercellular) is transmitted through specialized domains of lipids (micro or macrodomains) of the cell membrane. For some years, these domains have been called "rafts" [45], even if they were originally described much earlier [46] by researchers specialized in lipid dynamics.

Sphingolipids (Figure 3), known to be receptors for a number of vegetal and bacterial toxins and for viruses [47], are the most important components of these domains, namely glycosphingolipids with their sugar component that appears to play a specific role at the interface between the fatty acyl chains and the aqueous solvent [48]. In the Central Nervous system (CNS), as well as in some specialized cells like epithelial cells, the presence of a relatively high amount of glycosphingolipids has been described and studied for their role in these cells, in relation to their structure and dynamics [49] [50].

Wallace et al. [51] [52] have proposed a theory for the role of lipids in the CNS computing capacity and in memory, based on quantum mechanics. In addition, in the function of synaptic vesicles in the CNS, a quantum mechanical solution has been proposed [53] for the transmission of the neural influx through synaptic membranes. Such functions of these lipids characteristic of the neural membranes are to be linked to new advances in artificial intelligence [54] [55]. These authors have built a cortex-inspired silicon circuit that multiplies and selects features in its input, using a network of neuron-like elements. Molecules of the type of neural lipids are active in the networks of neurons that select and multiply input signals [56]. As in the computer technology, the gate and interface functions permit the transfer of information. Here the neural lipids, with their specific structures and properties, are the key for understanding information transfer and memory [57] [58].

\subsection{Cholesterol}

Cholesterol is an essential structural component in the cell membranes of most vertebrates [59], with other sterols being found in vegetal cells. The biophysical characteristics of these sterol molecules make them special components of the membrane. The polycyclic hydrophobic part of cholesterol's structure penetrates inside the fatty acid chains of the lipids, and contributes in a negative way to the "fluidity" of the membrane by modifying the "order parameter" [5].

\section{Structure of the Lipid Bilayer from Membranes and Vesicles}

It seems interesting to underline the common structural, liquid crystal characteristics of cell membrane and 
membrane vesicles, whatsoever their different lipid and protein composition. The structure of the lipid bilayer of cell membranes and vesicles plays an essential role in the function of these organelles in the cell. Such a structure is stabilized by the participation of the different molecular components in interaction, namely lipids and proteins.

Based on the model of biological membrane structure, synthetic nanostructures: "liquid-crystalline fullerodendrimers" have been constructed (Figure 4) [60] [61]. The authors underline the interest of development of new classes of liquid-crystalline materials in which information at the molecular level is transferred from an initiator core to the periphery at the nanometer scale. Indeed, such molecular devices would show outstanding performance by combining the electrochemical and photophysical properties of the components.

Indeed, the liquid crystalline structure of the biological lipid bilayer can be compared to the smectic A, lyotropic systems formed by amphiphiles and water.

Amphiphilic molecules, like lipids, associate in such pattern that there is a minimum of free energy. There are several geometric patterns described and by addition of water, the crystal structure collapses into the formation of a lamellar structure [62]. These systems have the characteristics of liquids along the plane of the layer and respond like solids to a force perpendicular to the layers; the deformed state can be adopted without the density of molecules per unit surface of the layer being fundamentally altered, while the thickness of the layers is only slightly modified [63]. The characteristics of elasticity [64]-[66] linked to the deformability of the lipid bilayer, are determinant for the formation of vesicles from a cell membrane, as well as for their fusion and fission [42] [67]. That allows a drastic change in the radius of curvature from the cell to the vesicle membrane, with exchange of lipids from internal vesicles with those of the reconstituted cell membrane.

The miscibility rule in these structures, analogues to liquids, applied only for a molecule of the same structure as the one in the bilayer: lipid molecules in the present case. Liquid diffusion, which tends to make the densities uniform, is the essential phenomenon. In the case of inclusion of a molecule of a different nature and structure, a protein for instance, the local change of symmetry induces long-range effects that distort the layer and create twists. In the liquid crystal model of cell membranes, transient lipid domains of specific type of lipids [43], which display positional and orientational order, have been described [46] as being limited by proteins or by protein-cholesterol complexes, and accounted for as defects in the lattice. The privileged sites for the formation of accumulations of these lipids would be defects as in a solid crystal.

Some of these properties of the liquid crystal structure of biological membranes and vesicles appear fundamental to understand their formation and organization, and eventually their functions [67]. It is interesting to report here the function of neural membranes in the binding of neurotransmitters and other ligands [52]. These membranes, rich in the different types of glycosphingolipids, have been regarded as a lipid molecular lattice,

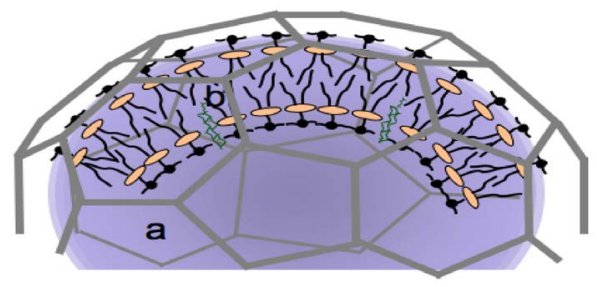

A

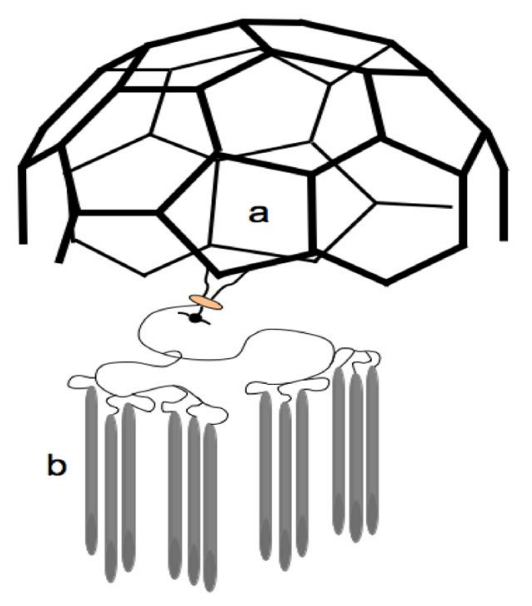

B

Figure 4. Schematic comparison of biological coated vesicles and synthetic liquid crystalline fullerodendrimer. A: Coated vesicles: carbon coat a surrounding the liquid crystalline lipid bilayer b-from [5]-; B: Liquid crystalline fullerodendrimer: carbon coat a and liquid crystalline material b-from [61]. 
which displays phase transitions between liquid and gel states on a time scale of picoseconds and in lipid domains of length of $100-1000 \mathrm{~A}^{\circ}$. Such transitions are associated with high membrane permeability to $\mathrm{Na}^{+}$, cholesterol and other ionic and molecular species and hydration-layer formation on the outer membrane surface that govern their function.

The "structured water" participates by an important entropy contribution to the charge transfer from the polar, neutral and charged amino-acid residues to the sugar ring of the glycolipids [48] [68]. Thus, lipid dynamics in such structure appears to play a key role in the regulation of protein-lipid interaction, in the function of the membranes, and in the formation of all types of vesicles, whether external vesicles of intercellular transport or secretion, or internal vesicles for intracellular transfer of material and information.

Any signal from outside the cell will be received and transduced [69] through the lipid bilayer of the cell membrane, whose lipid composition and transmembrane and proximal membrane proteins govern the dynamics of this process [42] [58]. Therefore, the lipid composition and the characteristic structure of the different cell membranes, as well as those of the vesicles formed from different types of cell will be determinant for their specific nature and function [12] [42].

\section{Protein-Lipid Interactions}

As mentioned above, the inclusion in lipids of molecules of a different nature and structure, like proteins, induces long-range effects that distort the lipid layer and create twists.

In the liquid crystal model for cell membranes, transient lipid domains [43] have been described [46], limited by proteins or by protein-cholesterol complexes. But what probably determines the nature of the dispersion of protein molecules within biological membranes, but also of ions, sterols, solutes of the surrounding water, would be the selective affinity of different parts of these molecules with different parts of the lipid host molecules [5] [70]. The paraffinic parts of the lipids attract each other as in the case of cholesterol, whereas the aromatic portions are repulsed [63] [71]. If the proteins are able to modify the structure of the lipid bilayer, the protein-lipid interaction leads to a specific structure for the intra-membranous portion, as well as for the membrane proximal sequences of these proteins [40] [72] [73].

\section{Conclusions}

As a conclusion, it seems worth to stress the electrochemical properties of the cell membranes: the network of charged-positive, negative- or neutral polar heads, which constitutes the barrier of electrical potential that interacts with the external and internal aqueous medium, ions and all solutes [44]. The lipid bilayer, providing a hydrophobic barrier separating the intra- from the extra-cellular aqueous compartment, has a negative charge on both sides, mainly due to the negatively charged phospholipids. The surface negative charges are provided by a variety of molecules inserted in, or attached to the membrane (proteins, glycolipids, proteoglycans), which contributes to the charge density. On each side of the membrane, there is a positive ionic cloud facing the negative charge layer and providing the system with electroneutrality.

Such a structure has been reproduced in the construction of synthetic nanostructures such as "liquid-crystalline fullerodendrimers" [60] [61]. In these new classes of liquid-crystalline materials, information at the molecular level is transferred from an initiator core to the periphery at the nanometer scale. Indeed, such molecular devices would show outstanding performance by combining the electrochemical and photophysical properties of the components. A schematic comparison of the image of such synthetic material (see Figure 4B made from [61]), with the representation of the clathrin-coated vesicle, as observed by electron microscopy [5] (see Figure 4A made from [5]) appears very suggestive of the important role of the lipid structure as biological vehicle of information.

\section{References}

[1] Forterre, P. and Gribaldo, S. (2007) The Origin of Modern Terrestrial Life. HFSP Journal, 1, 156-168. http://www.ncbi.nlm.nih.gov/pubmed/19404443

[2] Tatischeff, I., Bomsel, M., de Paillerets, C., Durand, H., Geny, B., Segretain, D., Turpin, E. and Alfsen, A. (1998) Dictyostelium Discoideum Cells Shed Vesicles with Associated DNA and Vital Stain Hoechst 33342. Cellular and Molecular Life Sciences, 54, 476-487. http://dx.doi.org/10.1007/s000180050176

[3] Huang, X.H., Bomsel, M., de Paillerets, C., Weintraub, H. and Alfsen, A. (1990) Biochemical Characterization of Al- 
gal Coated Vesicles. Biochimie, 72, 41-49. http://dx.doi.org/10.1016/0300-9084(90)90171-C

[4] Hugel, B., Martinez, M.C., Kunzelmann, C. and Freyssinet, J.M. (2005) Membrane Microparticles: Two Sides of the Coin. Physiology (Bethesda), 20, 22-27. http://dx.doi.org/10.1152/physiol.00029.2004

[5] Alfsen, A. (1989) Membrane Dynamics and Molecular Traffic and Sorting in Mammalian Cells. Progress in Biophysics and Molecular Biology, 54, 145-157. http://dx.doi.org/10.1016/0079-6107(89)90014-X

[6] Deloche, O. and Schekman, R. (2002) VPS10p Cycles between the TGN and the Late Endosome via the Plasma Membrane in Clathrin Mutants. Molecular Biology of the Cell, 13, 4296-4307. http://dx.doi.org/10.1091/mbc.02-07-0105

[7] Pellet, P.A., Dietrich, F., Bewersdorf, J., Rothman, J.E. and Lavieu, G. (2013) Inter-Golgi Transport Mediated by COPI-Containing Vesicles Carrying Small Cargoes. ELife, 2, e01296. www.ncbi.nlm.nih.gov/pubmed/24137546

[8] Stamnes, M.A., Craighead, M.W., Hoe, M.H., Lampen, N., Geromanos, S., Tempst, P. and Rothman, J.E. (1995) An Integral Membrane Component of Coatomer-Coated Transport Vesicles Defines a Family of Proteins Involved in Budding. Proceeding of the National Academy of Sciences of the USA, 92, 8011-8015.

http://dx.doi.org/10.1073/pnas.92.17.8011

[9] Zhou, P., Bacaj, T., Yang, X., Pang, Z.P. and Südhof, T.C. (2002) Lipid-Anchored SNAREs Lacking Transmembrane Regions Fully Support Membrane Fusion During Neurotransmitter Release. Neuron, 80, 470-483. http://dx.doi.org/10.1016/j.neuron.2013.09.010

[10] Zimmermann, H., Volknandt, W., Henkel, A., Bonzelius, F., Janetzko, A. and Kanaseki, T. (1989) The Synaptic Vesicle Membrane: Origin, Axonal Distribution, Protein Components, Exocytosis and Recycling. Cell Biology International Reports, 13, 993-1006. http://dx.doi.org/10.1016/0309-1651(89)90015-5

[11] de Paillerets, C., Bomsel, M., Weintraub, H., Pépin, D. and Alfsen, A. (1987) Clustering in Coated Vesicles of Polyunsaturated Phospholipids Segregated from Plasma and Golgi Membranes of Adrenocortical Cells. FEBS Letters, 219, 113-118. http://dx.doi.org/10.1016/0014-5793(87)81201-2

[12] Munro, S. (2004) Organelle Identity and the Organization of Membrane Traffic. Nature Cell Biology, 6, 469-472. http://dx.doi.org/10.1038/ncb0604-469

[13] Soler, N., Marguet, E., Verbavatz, J.M. and Forterre, P. (2008) Virus-Like Vesicles and Extracellular DNA Produced by Hyperthermophilic Archaea of the Order Thermococcales. Research in Microbiology, 159, 390-399. http://dx.doi.org/10.1016/j.resmic.2008.04.015

[14] Beveridge, T.J. (1999) Structures of Gram-Negative Cell Walls and their Derived Membrane Vesicles. Journal of Bacteriology, 181, 4725-4733. http://www.ncbi.nlm.nih.gov/pubmed/10438737

[15] Mashburn, L.M. and Whiteley, M. (2005) Membrane Vesicles Traffic Signals and Facilitate Group Activities in a Prokaryote. Nature, 437, 422-425. http://dx.doi.org/10.1038/nature03925

[16] Kuehn, M.J. and Kesty, N.C. (2005) Bacterial Outer Membrane Vesicles and the Host-Pathogen Interaction. Genes \& Development, 19, 2645-2655. http://dx.doi.org/10.1101/gad.1299905

[17] Lavialle, F., Deshayes, S., Gonnet, F., Larquet, E., Kruglick, S.G., Boisset, N., Daniel, R., Alfsen, A. and Tatischeff, I. (2009) Nanovesicles Released by Dictyostelium Cells: A Potential Carrier for Drug Delivery. International Journal of Pharmacy, 380, 206-215. hhttp://dx.doi.org/10.1016/j.ijpharm.2009.06.039

[18] Tatischeff, I., Lavialle, F., Pigaglio-Deshayes, S., Pechoux-Longin, C., Chinsky, L. and Alfsen, A. (2008) Dictyostelium Extracellular Vesicles containing Hoechst 33342 Transfer the Dye into the Nuclei of Living Cells: A Fluorescence Study. Journal of Fluorescence, 18, 319-328. http://dx.doi.org/10.1007/s10895-007-0271-4

[19] Gruenberg, J. (2003) Lipids in Endocytic Membrane Transport and Sorting. Current Opinion in Cell Biology, 15, 382388. http://dx.doi.org/10.1016/S0955-0674(03)00078-4

[20] Kobayashi, T., Stang, E., Fang, K.S., de Moerloose, P., Parton, R.G. and Gruenberg, J. (1998) A Lipid Associated with the Antiphospholipid Syndrome Regulates Endosome Structure and Function. Nature, 392, 193-197. http://www.ncbi.nlm.nih.gov/pubmed/9515966 http://dx.doi.org/10.1038/32440

[21] Tatischeff, I. (2013) Assets of the Non-Pathogenic Microorganism Dictyostelium discoideum as a Model for the Study of Eukaryotic Extracellular Vesicles. F1000Research, 2, 73. http://www.ncbi.nlm.nih.gov/pubmed/24327885

[22] Tatischeff, I. and Alfsen, A. (2011) A New Biological Strategy for Drug Delivery: Eucaryotic Cell-Derived Nanovesicles. Journal of Biomaterials and Nanobiotechnology, 2, 494-499. http://dx.doi.org/10.4236/jbnb.2011.225060

[23] Gould, S.J. and Raposo, G. (2013) As We Wait: Coping with an Imperfect Nomenclature for Extracellular Vesicles. Journal of Extracellular Vesicles, 2, 20389. http://www.ncbi.nlm.nih.gov/pubmed/24009890

[24] Mathivanan, S., Ji, H. and Simpson, R.J. (2010) Exosomes: Extracellular Organelles Important in Intercellular Communication. Journal of Proteomics, 73, 1907-1920. http://dx.doi.org/10.1016/j.jprot.2010.06.006

[25] Heijnen, H.F., Schiel, A.E., Fijnheer, R., Geuze, H.J. and Sixma, J.J. (1999) Activated Platelets Release Two Types of Membrane Vesicles: Microvesicles by Surface Shedding and Exosomes Derived from Exocytosis of Multivesicular 
Bodies and Alpha-Granules. Blood, 94, 3791-3799. http://www.ncbi.nlm.nih.gov/pubmed/10572093

[26] Papp, K., Vegh, P., Prechl, J., Kerekes, K., Kovacs, J., Csikos, G., Bajtay, Z. and Erdei, A. (2008) B Lymphocytes and Macrophages Release Cell Membrane Deposited C3-Fragments on Exosomes with T Cell Response-Enhancing Capacity. Molecular Immunology, 45, 2343-2351. http://dx.doi.org/10.1016/j.molimm.2007.11.021

[27] Denzer, K., van Eijk, M., Kleijmeer, M.J., Jakobson, E., de Groot, C. and Geuze, H.J. (2000) Follicular Dendritic Cells Carry MHC Class II-Expressing Microvesicles at Their Surface. Journal of Immunology, 165, 1259-1265. http://www.ncbi.nlm.nih.gov/pubmed/10903724

[28] Segura, E., Amigorena, S. and Thery, C. (2005) Mature Dendritic Cells Secrete Exosomes with Strong Ability to Induce Antigen-Specific Effector Immune Responses. Blood Cells, Molecules, and Diseases, 35, 211-226. http://dx.doi.org/10.1016/j.bcmd.2005.05.003

[29] Thery, C., Boussac, M., Veron, P., Ricciardi-Castagnoli, P., Raposo, G., Garin, J. and Amigorena, S. (2001) Proteomic Analysis of Dendritic Cell-Derived Exosomes: A Secreted Subcellular Compartment Distinct from Apoptotic Vesicles. Journal of Immunology, 166, 7309-7318. http://www.ncbi.nlm.nih.gov/pubmed/11390481

[30] van Niel, G., Raposo, G., Candalh, C., Boussac, M., Hershberg, R., Cerf-Bensussan, N. and Heyman, M. (2001) Intestinal Epithelial Cells Secrete Exosome-Like Vesicles. Gastroenterology, 121, 337-349.

http://dx.doi.org/10.1053/gast.2001.26263

[31] Denzer, K., Kleijmeer, M.J., Heijnen, H.F., Stoorvogel, W. and Geuze, H.J. (2000) Exosome: from Internal Vesicle of the Multivesicular Body to Intercellular Signaling Device. Journal of Cell Science, 113, 3365-3374. http://www.ncbi.nlm.nih.gov/pubmed/10984428

[32] Fevrier, B. and Raposo, G. (2004) Exosomes: Endosomal-Derived Vesicles Shipping Extracellular Messages. Current Opinion in Cell Biology, 16, 415-421. http://dx.doi.org/10.1016/j.ceb.2004.06.003

[33] Kobayashi, T., Beuchat, M.H., Chevallier, J., Makino, A., Mayran, N., Escola, J.M., Lebrand, C., Cosson, P., Kobayashi, T. and Gruenberg, J. (2002) Separation and Characterization of Late Endosomal Membrane Domains. The Journal of Biological Chemistry, 277, 32157-32164. http://dx.doi.org/10.1074/jbc.M202838200

[34] Kobayashi, T., Gu, F. and Gruenberg, J. (1998) Lipids, Lipid Domains and Lipid-Protein Interactions in Endocytic Membrane Traffic. Seminars in Cell and Developmental Biology, 9, 517-526. http://dx.doi.org/10.1006/scdb.1998.0257

[35] Matsuo, H., Chevallier, J., Mayran, N., Le Blanc, I., Ferguson, C., Faure, J., Blanc, N.S., Matile, S., Dubochet, J., Sadoul, R., Parton, R.G., Vilbois, F. and Gruenberg, J. (2004) Role of LBPA and Alix in Multivesicular Liposome Formation and Endosome Organization. Science, 303, 531-534. http://dx.doi.org/10.1126/science.1092425

[36] Stoorvogel, W., Kleijmeer, M.J., Geuze, H.J. and Raposo, G. (2002) The Biogenesis and Functions of Exosomes. Traffic, 3, 321-330. http://dx.doi.org/10.1034/j.1600-0854.2002.30502.x

[37] Trams, E.G., Lauter, C.J., Salem Jr., N. and Heine, U. (1981) Exfoliation of Membrane Ecto-Enzymes in the Form of Microvesicles. Biochimica et Biophysica Acta (BBA)—Biomembranes, 645, 163-170. http://dx.doi.org/10.1016/0005-2736(81)90512-5

[38] Bomsel, M. and Alfsen, A. (2003) Entry of Viruses through the Epithelial Barrier: Pathogenic Trickery. Nature Reviews. Molecular Cell Biology, 4, 57-68. http://dx.doi.org/10.1038/nrm1005

[39] Brugger, B., Glass, B., Haberkant, P., Leibrecht, I., Wieland, F.T. and Krausslich, H.G. (2006) The HIV Lipidome: A Raft with an Unusual Composition. Proceedings of the National Academy of Sciences of the USA, 103, 2641-2646. http://dx.doi.org/10.1073/pnas.0511136103

[40] Coutant, J., Yu, H., Clement, M.J., Alfsen, A., Toma, F., Curmi, P.A. and Bomsel, M. (2008) Both Lipid Environment and $\mathrm{pH}$ Are Critical for Determining Physiological Solution Structure of 3-D-Conserved Epitopes of the HIV-1 gp41-MPER Peptide P1. Faseb Journal, 22, 4338-4351. http://dx.doi.org/10.1096/fj.08-113142

[41] Raulin, J. (2000) Lipids and Retroviruses. Lipids, 35, 123-130. http://dx.doi.org/10.1007/BF02664760

[42] van Meer G. and Sprong, H. (2004) Membrane Lipids and Vesicular Traffic. Current Opinion in Cell Biology, 16,. 373-378. http://dx.doi.org/10.1016/j.ceb.2004.06.004

[43] van Meer, G., Voelker, D.R. and Feigenson, G.W. (2008) Membrane Lipids: Where They Are and How They Behave. Nature Reviews. Molecular Cell Biology, 9, 112-124. http://dx.doi.org/10.1038/nrm2330

[44] Olivotto, M., Arcangeli, A., Carla, M. and Wanke, E. (1996) Electric Fields at the Plasma Membrane Level: A Neglected Element in the Mechanisms of Cell Signalling. Bioessays, 18, 495-504. http://dx.doi.org/10.1002/bies.950180612

[45] Simons, K. and Ikonen, E. (1997) Functional Rafts in Cell Membranes. Nature, 387, 569-572. http://dx.doi.org/10.1038/42408 
[46] Helfrich, W. (1989) Hats and Saddles in Lipid Membranes. Liquid Crystals, 5, 1647-1658. http://dx.doi.org/10.1080/02678298908045675

[47] Hannun, Y.A. and Obeid, L.M. (2008) Principles of Bioactive Lipid Signalling: Lessons from Sphingolipids. Nature Reviews. Molecular Cell Biology, 9, 139-150. http://dx.doi.org/10.1038/nrm2329

[48] Franks, F. and Symons, M.C.R. (1977) Solvation and Conformational Effects in Aqueous Solutions of Biopolymer Analogues. Philosophical Transactions of the Royal Society of B: Biological Sciences, 278, 33-57. http://dx.doi.org/10.1098/rstb.1977.0030

[49] Coetzee, T., Suzuki, K. and Popko, B. (1998) New Perspectives on the Function of Myelin Galactolipids. Trends in Neurosciences, 21, 126-130. http://dx.doi.org/10.1016/S0166-2236(97)01178-8

[50] Simons, K. and van Meer, G. (1988) Lipid Sorting in Epithelial Cells. Biochemistry, 27, 6197-6202. http://dx.doi.org/10.1021/bi00417a001

[51] Wallace, R. (1996) Microcomputational Evolution of the Neural Membrane. Nanobiology, 4, 25-38.

[52] Wallace, R., Price, H. and Breitbeil, F. (1998) Toward a Charge-Transfer Model of Neuromolecular Computing. International Journal of Quantum Chemistry, 69, 3-10. http://dx.doi.org/10.1002/(SICI)1097-461X(1998)69:1<3::AID-QUA2>3.0.CO;2-Z

[53] Eccles, J. (1990) A Unitary Hypothesis of Mind-Brain Interaction in the Cerebral Cortex. Proceedings of the Royal Society B: Biological Sciences, 240, 433-451. http://dx.doi.org/10.1098/rspb.1990.0047

[54] Gershenfeld, N.A. and Chuang, I.L. (1997) Bulk Spin-Resonance Quantum Computation. Science (New York), 275, 350-356. http://www.ncbi.nlm.nih.gov/pubmed/8994025

[55] Hahnloser, R.H., Sarpeshkar, R., Mahowald, R.M.A., Douglas, R.J. and Seung, H.S. (2000) Digital Selection and Analogue Amplification Coexist in a Cortex-Inspired Silicon Circuit. Nature, 405, 947-951. http://dx.doi.org/10.1038/35016072

[56] Diorio, C. and Rao, R.P. (2000) Computational Neuroscience: Neural Circuits in Silicon. Nature, 405, 891-892. http://dx.doi.org/10.1038/35016172

[57] Maycox, P.R., Hell, J.W. and Jahn, R. (1990) Amino Acid Neurotransmission: Spotlight on Synaptic Vesicles. Trends in Neurosciences, 13, 83-87. http://dx.doi.org/10.1016/0166-2236(90)90178-D

[58] Wymann, M.P. and Schneiter, R. (2008) Lipid Signalling in Disease. Nature Reviews. Molecular Cell Biology, 9, 162-176. http://dx.doi.org/10.1038/nrm2335

[59] Ikonen, E. (2008) Cellular Cholesterol Trafficking and Compartmentalization. Nature Reviews. Molecular Cell Biology, 9, 125-138. http://dx.doi.org/10.1038/nrm2336

[60] Guillon, D. and Deschenaux, R. (2002) New Classes of Liquid-Crystalline Materials. Current Opinion in Solid State Matter Sciences, 6, 515-525. http://dx.doi.org/10.1016/S1359-0286(03)00012-3

[61] Guillon, D., Donnio, B. and Deschenaux, R. (2009) Liquid-Crystalline Fullerodendrimers. In: Martín, N. and Giacalone F., Eds., Fullerene Polymers, Synthesis, Properties and Applications, Wiley-VCH Verlag GmbH \& Co. KGaA, Weinheim, 247-270. http://dx.doi.org/10.1002/9783527628742.ch11

[62] Brown, H.G. and Wolken, J.J. (1979) Structure of Liquid Crystals in Liquid Crystals and Biological Structures, Academic Press, Inc., Waltham, 1, 22-44.

[63] Kleman, M. (1983) Point, Lines and Walls in Liquid Crystals, Magnetic Systems and Various Ordered Media. John Wiley and Sons Limited, 114-128.

[64] Sackmann, E. and Träuble, H. (1972) Crystalline-Liquid Crystalline Phase Transition of Lipid Model Membranes. I. Use of Spin Labels and Optical Probes as Indicators of the Phase Transition. Journal of the American Chemical Society, 94, 4482-4491. http://dx.doi.org/10.1021/ja00768a013

[65] Sackmann, E. and Träuble, H. (1972) Crystalline-Liquid Crystalline Phase Transition of Lipid Model Membranes. II. Analysis of Electron Spin Resonance Spectra of Steroid Labels Incorporated into Lipid Membranes. Journal of the American Chemical Society, 94, 4492-4498. http://dx.doi.org/10.1021/ja00768a014

[66] Träuble, H. and Sackmann, E. (1972) Crystalline-liquid Crystaline Phase Transition of Lipid Model Membranes. III. Structure of a Steroid-Lecithin System below and above the Lipid-Phase Transition. Journal of the American Chemical Society, 94, 4499-4510. http://dx.doi.org/10.1021/ja00768a015

[67] Chernomordik, L., Kozlov, M.M. and Zimmerberg, J. (1995) Lipids in Biological Membrane Fusion. Journal of Membrane Biology, 146, 1-14. http://dx.doi.org/10.1007/BF00232676

[68] Lemieux, L., McBride, A. and Hand, J.W. (1996) Calculation of Electrical Potentials on the Surface of a Realistic Head Model by Finite Differences. Physics in Medicine and Biology, 41, 1079-1091. http://dx.doi.org/10.1088/0031-9155/41/7/001 
[69] Casey, P.J. (1995) Protein Lipidation in Cell Signaling. Science (New York), 268, 221-225. http://www.ncbi.nlm.nih.gov/pubmed/7716512

[70] Bouligand, Y. (1999) Remarks on the Geometry of Micelles, Bilayers and Cell Membranes. Liquid Crystals, 26, 501-515. http://dx.doi.org/10.1080/026782999204949

[71] Alfsen, A., de Paillerets, C., Prasad, K., Nandi, P.K., Lippoldt, R.E. and Edelhoch, H. (1984) Organization and Dynamics of Lipids in Bovine Brain Coated and Uncoated Vesicles. European Biophysical Journal, 11, 129-136. http://dx.doi.org/10.1007/BF00276628

[72] Funamoto, S., Meili, R., Lee, S., Parry, L. and Firtel, R.A. (2002) Spatial and Temporal Regulation of 3-Phosphoinositides by PI 3-Kinase and PTEN Mediates Chemotaxis. Cell, 109, 611-623. http://dx.doi.org/10.1016/S0092-8674(02)00755-9

[73] Klein, D.E., Stayrook, S.E., Shi, F., Narayan, K. and Lemmon, M.A. (2008) Structural Basis for EGFR Ligand Sequestration by Argos. Nature, 453, 1271-1275. http://dx.doi.org/10.1038/nature06978. 